\title{
Self-plagiarism case prompts calls for agencies to tighten rules
}

\author{
Technology is bringing down instances of duplication, despite variability in oversight.
}

\section{BY EUGENIE SAMUEL REICH}

$\mathrm{I}$ s plagiarism a sin if the duplicated material is one's own? Self-plagiarism may seem a smaller infraction than stealing another author's work, but the practice is under increasing scrutiny, as the eruption two weeks ago of a long-standing controversy at Queen's University in Kingston, Canada, makes clear.

Colleagues of Reginald Smith, an emeritus professor of mechanical and materials engineering at Queen's, say that up to 20 of Smith's papers contain material copied without acknowledgment from previous publications. University officials first learned of the duplications in 2005, and they eventually led to an investigation by the Natural Sciences and Engineering Research Council (NSERC), which funded some of Smith's work, including experiments on board the US space shuttles. Although Smith avoided censure for research misconduct, three papers were subsequently retracted by the Annals of the New York Academy of Sciences ${ }^{1}$ and one by the Journal of Materials Processing Technology ${ }^{2}$. The situation was recently made public in news reports and has led to calls for stronger powers by funding agencies in Canada to discipline researchers who engage in the practice.

"He was a very good scientist, but something happened and he got into this business of duplicating papers," says Chris Pickles, a metallurgist at Queen's who raised concerns about Smith's publication practices after spotting some duplications under Smith's name while searching an online database. Smith referred a request for comment to his lawyer, Ken Clark of law firm Aird and Berlis in Toronto, Canada, who notes that many of the republications duplicated material from conference proceedings, which in an earlier epoch would not usually have been published. He also notes that Smith is retired, and does not stand to gain financially from his republications.

Many researchers say that republication without citation violates the premise that each scientific paper should be an original contribution. It can also serve to falsely inflate a researcher's CV by suggesting a higher level

$\rightarrow$ NATURE.COM Journals step up plagiarism policing: go.nature.com/kdmlsa by the scientific community, "we would expect that results, discussion and the abstract present novel results", says Harold Garner, a bioinformatician at Virginia Polytechnic Institute and State University in Blacksburg. Garner's research group used an automated software tool to check the biomedical literature for duplicated text, and identified more than 79,000 pairs of article abstracts and titles containing duplicated wording. He says work on the database of partly duplicated articles called Déjà vu (go.nature.com/hgq2t4) — has

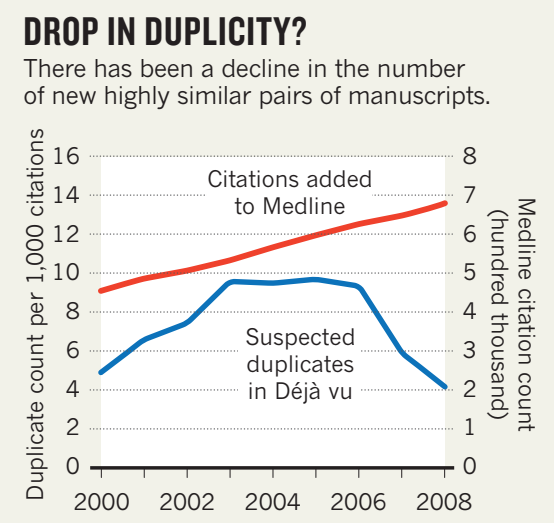

led to close to 100 retractions by journal editors who found the reuse improper. An analysis by Garner in the press at Urologic Oncology $y^{3}$ shows that while the total quantity of biomedical literature has risen steadily since 2000 , cases of republication stopped rising after 2003 and fell sharply between 2006 and 2008 (see graph). "It actually does look like it's getting better," says Garner. "People who would ordinarily step across the line are not doing it."

$\mathrm{He}$ credits increased vigilance by journal editors who are using his free tool or commercially available software to check submissions for repeated text and halt dubious papers before they reach publication.

NSERC's policy on integrity in research makes no specific reference to plagiarism or self-plagiarism, which has led to calls for tougher rules in the wake of the publicity over Smith's case. In the United States, the National Science Foundation (NSF) takes a strong stance on plagiarism in general, says Christine Boesz, who was inspector-general at the NSF from 1999 until 2008. "The NSF got into the plagiarism game early," she says. Numbers obtained by Nature under the US Freedom of Information Act show that, since 2007, the agency has found between 5 and 13 cases of plagiarism each year. In contrast, the US Department of Health and Human Services's Office of Research Integrity (ORI), which is responsible for overseeing alleged plagiarism associated with National Institutes of Health research, has reported no cases of plagiarism of text over the past three years, but has found up to 14 scientists a year guilty of falsification or fabrication of data (see table).

Ann Bradley, a spokeswoman for the ORI, says the office's working definition of plagiarism (go.nature.com $/ \mathrm{p} 15 \mathrm{kcu}$ ) excludes minor cases. Nick Steneck, director of research ethics and integrity at the University of Michigan in Ann Arbor, says authorities worldwide should adopt a uniform misconduct policy that provides clear guidance not only on data falsification and fabrication but also on lesser ethical breaches - such as self-plagiarism .

1. Braaten, D. Ann. NY Acad. Sci. 1176, 228 (2009).

2. Smith, R. W., DeMonte, A. \& Mackay, W. B. F.

J. Mater. Process. Tech. 153-154, 589-595 (2004).

3. Garner, H. R. Urol. Oncol.-Semin. Ori. doi:10.1016/j. urolonc.2010.09.016 (in the press).

\section{CASES OF MISCONDUCT AND PLAGIARISM AS REPORTED BY US RESEARCH AGENCIES}

\begin{tabular}{|c|c|c|c|c|c|c|}
\hline & \multicolumn{3}{|c|}{ Office of Research Integrity (ORI) } & \multicolumn{3}{|c|}{ National Science Foundation (NSF) } \\
\hline & 2008 & 2009 & 2010 & 2008 & 2009 & 2010 \\
\hline $\begin{array}{l}\text { Debarments for } \\
\text { falsification/fabrication }\end{array}$ & 2 & 1 & 3 & 1 & 2 & 3 \\
\hline Debarments for plagiarism & 0 & 0 & 0 & 0 & 4 & 2 \\
\hline $\begin{array}{l}\text { Findings of falsification/ } \\
\text { fabrication }\end{array}$ & 7 & 14 & 7 & 1 & 1 & 2 \\
\hline Findings of plagiarism & 0 & 0 & 0 & 5 & 13 & 10 \\
\hline
\end{tabular}

Number of funded researchers: National Institutes of Health (ORI) 325,000; NSF 98,820 (2010). 2010 data run until August. of productivity. And although the repetition of the methods section of a paper is not necessarily considered inappropriate 

Japanese programme

\section{Akatsuki mission on hold for six years before next attempt to approach planet.}
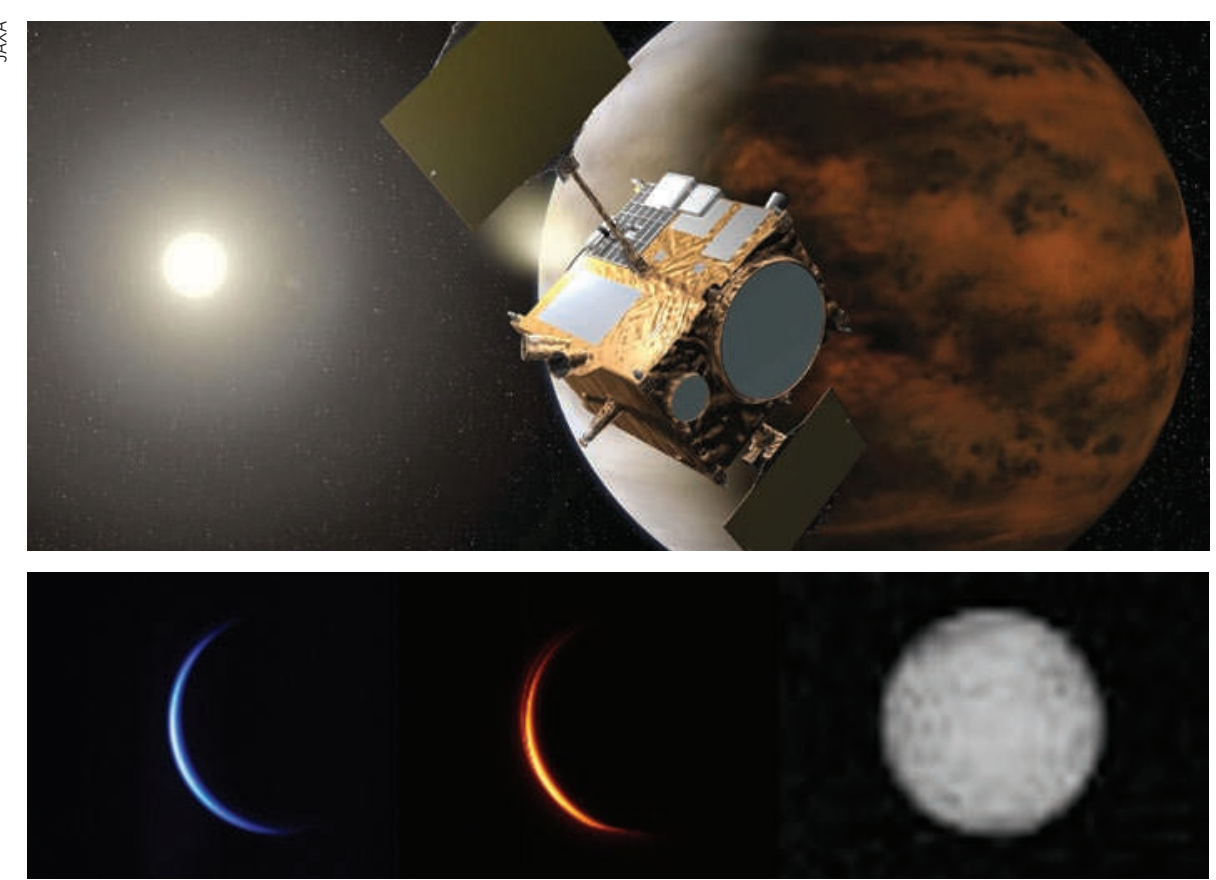

Top: the craft was set to monitor Venus's atmosphere. Bottom: images taken as Akatsuki sped away.

\section{BY DAVID CYRANOSKI}

$\mathrm{F}$ ew events can be as gut-wrenching for a planetary scientist as a multi-milliondollar spacecraft going silent while executing a crucial manoeuvre. Loss of signal at such times usually spells disaster, and the spacecraft may never be heard from again.

Researchers and engineers working with Japan's Akatsuki spacecraft were spared that worst-case scenario on 6 December. Although Akatsuki failed to make contact for more than an hour after the scheduled engine burn that was to place it in orbit around Venus, it did eventually call home. But the news was not promising. Not only had Akatsuki been tumbling out of control for a period of time, it had failed to enter orbit. It will now have to circle the Sun for six years before it gets a second chance.

The failure derails an ambitious programme of research into Venus's atmosphere, and marks the third time that the Japan Aerospace Exploration Agency (JAXA) has battled mechanical problems on a mission to another Solar System body. In 1998, a faulty valve caused a loss of fuel on JAXA's Nozomi spacecraft, which ultimately prevented it from orbiting Mars. And the Hayabusa probe, which returned a minute quantity of asteroidal material to Earth this year, experienced a variety of near-fatal problems.

At a press conference on 10 December, officials reported that Akatsuki's engines fired for less than 3 minutes, far short of the 9 minutes and 20 seconds required to slip into orbit. "We are trying our best to get rid of any preconceived notions and figure out what happened," a project team member told Nature.

Akatsuki was to scour Venus with an infrared camera for evidence of volcanic activity, study lightning in the atmosphere and investigate the dense cloud layer that hides the planet's surface from view. Its planned equatorial orbit - timed to match the 'super rotation' of Venus's atmosphere, which spins about 60 times faster than the planet beneath it - would have allowed it to follow the long-term evolution of features in the cloud layer. Such data would have complemented the global coverage of Venus Express, the European Space Agency (ESA) probe that has been orbiting Venus since 2006.

"This is very disappointing for all of us," says Håkan Svedhem, an ESA project scientist for Venus Express. "We had hoped to do

many things jointly."

Engineers will now pore over telemetry data from Akatsuki and conduct tests with backup hardware on Earth to try to identify the source of the failure. The spacecraft's fuel system is likely to get close scrutiny: Akatsuki uses the same two-fluid hydrazine-nitrogen tetroxide thruster as Nozomi, although the valve issue has been addressed.

A series of images taken as Akatsuki sped away from Venus shows that its cameras are working well and may yet be put to use if the spacecraft survives its unplanned detour. One hurdle faced by Nozomi on its second attempt to enter orbit - frozen fuel - will probably not affect Akatsuki, because of the probe's proximity to the sun. Solar radiation might, however, take a toll on the craft's sensitive instruments.

If Akatsuki does reach Venus in 2016, it might still be able to join forces with other probes. Last month, ESA agreed to extend the Venus Express mission to 2014, and it is considering a further extension to 2017 or 2018 , although this would require modifications

Akatsukifailed to make contact for more than an hour after ascheduled engine burn. to the craft's orbit to save fuel. Meanwhile, NASA is planning SAGE, a Venus lander that could launch in 2016.

"Understanding Venus is important because it informs us about the evolution of the climate on Earth," says Sanjay Limaye, an atmospheric scientist at the University of Wisconsin-Madison and a co-investigator on Akatsuki. "Not going into orbit now does not translate into a diminished interest in Venus, as the questions do not go away," he says.

\section{CORRECTION}

The News story 'Self-plagiarism case prompts calls for agencies to tighten rules' (Nature 468, 745; 2010) stated that Reginald Smith had escaped censure for research misconduct for publishing duplicate papers. In fact, Smith was formally reprimanded for reuse of published materials and data in multiple publications, although separate allegations of data falsification and plagiarism were not upheld. 